\title{
Geochemistry of thermal waters from various geothermal provinces of Algeria
}

\author{
CHENAKER $\mathrm{H}^{1}$, HOUHA B ${ }^{2}$, MOHAMADI MR ${ }^{3}$
}

${ }^{1}$ Scientific and Technical Research Centre in PhysicoChemical Analyses (CRAPC) Algeria drchenaker@yahoo.fr

${ }^{2}$ Laboratory water, environment and renewable energies, University of Khenchela, Algeria bhouha@yahoo.fr

${ }^{3}$ Geology Department - Faculty of Sciences University of Tunis El Manar redhaeco@hotmail.com

To improve our understanding of the origin of thermal water from North-Eastern Algeria, hydrochemical facies, isotopic characteristics to identify the major geochemical processes that affect water composition, for this purpose, a multidisciplinary approach was adopted, including hydrogeochemistry, isotope hydrology and principal component analysis (PCA).

Eleven samples collected from thermal springs in 2016 vary in temperature between 38 and $96{ }^{\circ} \mathrm{C}$, a near neutral $\mathrm{pH}$ and very high values of electrical conductivity. Two groundwater types were identified: highly mineralized $\mathrm{Na}-\mathrm{Cl}$ type representing the deep thermal waters and $\mathrm{Ca}-\mathrm{SO} 4$ type determined the presence of evaporite deposits (Triassic) along the circuit of upwelling.

The isotopic results $(\delta \mathrm{O} 18, \delta \mathrm{D})$ (respectively -9.95 to $-7.72 \%$ and from -61.99 to $-38.20 \%$ ) fall on the Global Meteoric Water Line (GMWL) indicate a meteoric origin of the thermal water (rains at higher altitude). The highest estimated reservoir temperatures are indicated by the CCG and $\mathrm{Na}-\mathrm{K}-\mathrm{Ca}$ geothermometer, while slightly lower estimates are obtained using silica geothermometers.

In order to know the state of fluid-mineral equilibrium, saturation index (SI) was used; the most of the thermal waters have Chalcedony and quartz near or slightly above the saturation limit for equilibrium. In present study, multivariate statistical method - Principal component analysis PCA - is used; PC1 (41\%) explains the minerality, (ionic composition), for which temperature is of secondary importance PC2 (18\%).

In terms of these physicochemical properties, thermal water of eastern Algeria are highly effective for the treatment of various diseases, in particular respiratory and rheumatic diseases. 